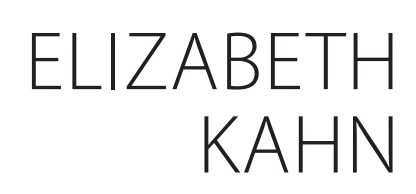

\title{
Injustice and Collectivization in World Politics ${ }^{1}$
}

\begin{abstract}
In Justice and Reconciliation in World Politics Catherine Lu endorses the idea that those who contribute to the reproduction of structural injustice have responsibilities to address that injustice (Lu, 2017). However, in the book, Lu does not explore the grounds and justification for recognising such a responsibility. In order to address this deficit, this paper proposes that those likely to contribute to the reproduction of structural injustice, in the future, have precautionary duties, in the present, that require them to take action aimed at preventing their future contribution. It is proposed that these 'collectivization duties' (Collins, 2013) require them to act responsively with a view to forming a collective that can end the structural injustice in question. This account recommends a collective-action solution alongside recognising that each socially connected agent is obliged to act. However, it does not entail that amorphous groups bear responsibilities and is appropriate in its attribution of blame, thus avoiding both Nussbaum's (2011) critique of perpetually forward-looking accounts and the 'agency objection' (Wringe, 2010).
\end{abstract}

Keywords: structural injustice; collectivization; liability model; responsibility; social-connection.

\section{Introduction}

Catherine Lu's Justice and Reconciliation in World Politics (2017) uses and develops Iris Young's concept of structural injustice (2011) in order to advance understandings of colonial injustice. In doing so the book demonstrates the limits of existing approaches and develops a practical theory that can serve activists, citizens and politicians in their efforts to address historic injustice and achieve successful reconciliation.

The book advances theories of structural injustice by focussing on cases in which injustice results from actions that comply with unjust social norms and formal rules. Whilst Young focuses on contemporary injustices that result from a variety of benign social processes, Lu focusses on historic cases in which the processes themselves were explicitly unjust.

$\mathrm{Lu}$ argues that those who currently participate in social processes that contribute to the reproduction of contemporary structural injustices with historic roots have responsibilities to address these injustices in various ways (Lu, 2017: 20). Lu's account could benefit from developing a clearer approach to responsibility that can explain why it should fall on those socially connected

1 Although many people contributed significantly to the development of this paper, I would particularly like to thank Maeve McKeown and Christopher Finlay who kindly read drafts of this paper and provided particularly valuable feedback. 
to structural injustice. Building on Lu's work, I provide an account of the obligations agents have with regards to structural injustice that defines 'social connection' and explains why it grounds moral demands to act.

I follow McKeown (2018) in recognising that contribution to the reproduction of background conditions through every day actions is what connects individuals to structural injustice. Yet, contra McKeown, and in keeping with Abdel-Nour's suggestion (2018), my understanding identifies some continuity between political responsibility for structures and moral responsibility for outcomes. However, rather than drawing on the controversial idea that mere causal connection to harm is morally relevant even when an agent has not committed any wrong-doing as Abdel-Nour does, I draw on the idea of precautionary duties to explain why individuals can be identified as having duties to act to try to prevent the continuance of structural injustice (Abdel-Nour, 2018; Williams, 1981). I suggest that individuals can be recognised as having these precautionary duties even in circumstances in which it would not be right to hold them outcome responsible for the injustice, if the injustice were to occur in spite of their best efforts. I propose that those who are likely to contribute causally to future structural injustice, by reproducing it, have precautionary duties that require them to take ex-ante action in the present to prevent it. I use Collins' concept of 'collectivization' (2013) to specify what individuals must do to address structural injustice.

I argue that the duties outlined honour Lu and Young's commitment to recommending a collective-action solution whilst recognising that each socially connected agent has an obligation to act. And note that the account avoids suggesting that an amorphous group bears responsibility, thus avoiding the 'agency objection' (Wringe, 2010). I also argue that these duties are appropriate in their attribution of blame, addressing the criticism offered by Nussbaum (2009) against Young's original account.

The structure of the paper is as follows. First, it is alleged that neither Young's Responsibility for Justice nor Lu's Justice and Reconciliation in World Politics make clear what precisely counts as social connection; and nor do they explain why such a connection constitutes sufficient grounds for assigning responsibility for addressing injustice. Next, building on the approach suggested by McKeown (2018), it is proposed that an agent is socially connected to structural injustice when they contribute to the reproduction of that injustice. It is argued that the likelihood of such a connection to future injustice (if reform does not take place) is sufficient to ground obligations to take action in the present aimed at lessening the chance of the injustice continuing. It is suggested that such action constitutes a reasonable precaution that agents can be morally required 
to take in order to reduce the chances of future causal connection to structural injustice. Why causal connection can ground precautionary duties but not duties to avoid contribution is then explained. It is then argued that Young's approach advocating 'essentially shared responsibility' is not the clearest way of expressing her idea that each member of the aggregate of agents causally connected to structural injustice is morally required to work towards addressing injustice through collective-action. It is proposed that the key points of Young's account can be better articulated using Collins' concept of a 'collectivization duty' (2013) and such an account is then outlined.

In keeping with Lu's suggestion that over time those who fail to take up political responsibility may be blamed (Lu, 2017: 258-259), my account makes clear the conditions under which agents should be considered blameworthy. It is explained that my approach avoids blaming agents for causally contributing to structural injustice when it would be unreasonable to expect them to avoid contributing. Instead the account judges agents on whether or not they take responsive action with a view to establishing a collective capable of addressing the structural injustice. The paper concludes by stressing the key differences between the proposed account and the liability model that Young explicitly rejected for dealing with structural injustice.

\section{Structural Injustice}

Lu follows Young in recognizing that social structures consist in 'the confluence of institutional rules and interactive routines, mobilization of resources, as well as physical structures such as buildings and roads' that provide 'background conditions for individual actions by presenting actors with options [...] providing channels that enable and constrain.' (Young, 2011: 102-130, 111-112; Lu, 2017: 34). She identifies social structure as naming the conditions in which agents interact and relate to themselves, each other and the world ( $\mathrm{Lu}, 2017: 34-36)$.

Sociologists use the concept of structure to explain how a society works: to map the self-reproducing elements of a society that persist over time. The different social positions within a society and the on-going relationships between them make up the structure. ${ }^{2}$ In keeping with this idea, Young describes social structure as a particular way of viewing the whole of society rather than a specific part of it (Young, 2011: 70). Her analysis suggests that agents experience much of this structure as an objective reality that constrains and enables them in particular ways (Young, 2011: 52-64). The structure also attaches different rewards and costs to different choices for agents in different positions. ${ }^{3}$ This means that a

2 For sociological discussions of the concept of structure see Merton (1968); Berger and Luckmann (1966); and Jenkins (1992). For another use of the idea of structure in political philosophy see Julius (2003).

3 For a discussion of how different positions involve different weights attached to different choices see Olsaretti (2009). 
social structure can be said to 'treat' different categories of people in different ways based on their social position. Young's analysis even suggests that the structure affects the desires, preferences and aims of different individuals in addition to shaping their options and opportunities. Lu draws on the idea of affecting the choices of agents in her discussion of how colonial norms and practices made it likely that individuals and states would commit interactional wrongs (Lu, 2017: 24). She also notes the importance of discourses in shaping action and the role of structures in shaping identities and aspirations (ibid.: 35).

Lu defines structural injustice as referring to 'institutions, norms, practices, and material conditions that play a causal or conditioning role in producing objectionable conduct or outcomes' (ibid.: 34). She notes that both formal and informal rules, norms and practices alongside social conditions situate social groups in inferior social positions that make them vulnerable to unjust treatment, structural indignity or objectionable social conditions (ibid.: 20, 35).

She uses the concept of structural injustice to support two major insights. First, she notes how the international order that recognised the rights of colonial powers facilitated colonial abuse by situating some people in social positions where they were intensely vulnerable to atrocities. Second, she picks up on the way in which contemporary ideas, ideologies and bias that relate to the colonial past alongside power relations and material conditions that are, to some extent, the result of colonial history come together with other contemporary social processes to place some groups of people in positions of inferiority. These positions are inferior in terms of access to resources and power, and social standing as well as being much more vulnerable to abuse. She notes that these contemporary structural injustices undermine the achievement of international justice (Lu, 2017: 26).

\section{Social Connection}

Social conditions make up the background within which agents act and are held morally responsible for their actions. In Responsibility for Justice (2011), Young explores the responsibilities agents have with regard to this background itself. She proposes that when we seek to identify responsibility for this background we should not use a liability approach that isolates some party as warranting blame or being liable for compensation on the basis of their causal relationship with an outcome. Instead she proposes that we recognise multiple agents who share a forward-looking and political responsibility to work together to lessen any injustices in this background by taking part in collective action.

A liability model of responsibility asks which consequences can legitimately be attributed to an individual. The liability approach can be used to find an agent 
guilty of a crime, liable for costs, or deserving of praise, reward or a penalty. When used in this way, it isolates agents who are causally related to the outcome, identifies them as morally responsible and absolves others of responsibility for the outcome in question. By contrast, Young proposes that responsibility with regards to structural injustice is more akin to responsibilities that come with a particular social role like teacher or citizen (Young, 2011: 104). In doing so, she implies that we should be concerned with remedial responsibility rather than outcome responsibility. ${ }^{4}$ Her social connection model suggests that those who are socially connected to on-going structural injustices have a forwardlooking, shared responsibility for lessening that injustice through collective action (ibid.:113). Thus, she argues that those socially connected to structural injustice share a remedial responsibility to overcome structural injustice: that is a responsibility to fulfil a certain role going forward rather than moral responsibility for a particular outcome that refers back in time to an earlier point.

Young does not explicitly define what social connection is; nor does she fully explain why it is that remedial responsibility can be assigned on the basis of social connection (McKeown 2018, 484). The way she and Lu talk about social connection suggest three possible understandings of social connection that I explore below. Although all three ways of defining social connection will, in many cases, pick out the same set of agents, each definition gives a different criterion for identifying those with remedial responsibility and suggests a different justification as to why forward-looking responsibility should be assigned to these agents.

Young notes that the social connection model shares with the liability model 'a reference to causes of wrongs in the form of structural processes that produce injustice' (2011: 105). She states that the reason why individuals bear (remedial) responsibility for structural injustice is that they 'contribute by their actions to the processes that produce unjust outcomes' (ibid.: 105). This suggests that causal connection to an injustice can ground remedial responsibility to lessen it even when it cannot ground liability or moral responsibility for the injustice. Lu draws on the idea that causal contribution grounds social connection in explaining that non-culpable agents who contribute to the production of unjust structural conditions bear political responsibility to reform their social practices so that they are more just ( $\mathrm{Lu}, 2017: 165,258)$. This assignment of remedial responsibility could be derived from the principle that causal contribution to injustice is morally significant (as suggested in Abdel-Nour, 2018). Below I

4 David Miller differentiates between responsibility for an outcome (outcome responsibility) and responsibility to take action to remedy a situation (remedial responsibility) (Miller, 2007: 84-104). For further discussion of the relationship between these two see Abdel-Nour, 2018. 
develop an account of why a principle of contribution can ground a remedial duty to prevent the continuance of structural injustice even when it cannot be used to attribute liability for that injustice.

However, causal contribution is not the only grounds that Young's account suggests connects responsibility-bearing agents to structural injustice. She also says that responsibility derives from participating in the diverse institutional processes that produce structural injustice (Young, 2011: 105). Lu also appeals to the concept of participation in social processes that constitute or contribute to structural injustice in order to ground duties with regards to structural injustice (Lu, 2017: 142, 166, 171, 172, 257, 258).

Young also suggests that belonging to a 'system of interdependent processes of cooperation and competition through which we seek benefits and aim to realise projects' grounds the responsibility to prevent future structural injustice (Young, 2011: 105). This suggests that what grounds the remedial responsibility to others to lessen structural injustice is the fact that we share a scheme of cooperation through which we aim to benefit and fulfil our aims. Young's account suggests that it is reasonable for members of such a scheme to demand that the scheme treat them fairly. Individuals also gain (or share in) a remedial responsibility to ensure that scheme treats others justly either by entering into a scheme, attempting to benefit from the scheme or actually benefiting from a scheme. Through any one of these acts, they may gain a duty to fulfil other participants demand that they be treated fairly by the scheme. This duty could be derived from a principle that forbids participating in, benefitting from or attempting to benefit from an unfair scheme of interaction. ${ }^{5}$ At some point Lu suggests that those who benefit by being privileged by the system that disadvantages others have a special duty to address the injustice, either because their advantaged position gives them the power to act, or because their benefit grounds a special responsibility (Young, 2011: 187, 96, 144; Lu, 2017: 170171;). However, Lu emphasises that this is not the sole criterion for assigning responsibility, because responsibilities to transform unjust structures also fall on those who are victims of the structural injustice (Lu, 2017: 171).

Finally, Young suggests that all those who simply 'dwell within a social

5 Candice Delmas' article on 'duties to resist injustice' suggests that the principle of fairness can ground duties to take action to oppose injustice that fall on those who benefit from that injustice. See Delmas (2014: 465-488). Inspired by this work an account could be developed to show why benefiting from an unfair set of practices can ground duties to oppose structural injustice. Rob Jubb's work suggests that duties could be based on participation in an unjust set of practices rather than contributing to an unjust structure (Jubb, 2012). I do not explore either of these ideas here but instead focus on contribution as this is the approach Young's work refers to most. The advantage of concentrating on contribution is that it is an approach that can (if it works) capture those who contribute to trends or unconscious biases as well as those who contribute to public practices. Thus, it can in many cases include agents that the participation account does not capture. 
structure' have a remedial responsibility to remedy any injustice that those structures cause (Young, 2011:105). Merely living within a structure gives us a remedial responsibility to ensure it is just, though it is not entirely clear from Young's analysis why this may be the case. Lu implies this kind of understanding in her discussion of how 'all agents in various social positions' have to work together to overcome structural injustice ( $\mathrm{Lu}, 2017$ : 171). It could be that merely living in a social environment comes with responsibilities regarding that environment: that dwelling within a social structure is just 'pregnant' with obligations to ensure that structure is just. ${ }^{6}$ Or it may be that we have special responsibilities regarding the structures we live within because they are in some sense our business: as Lu says (quoting Rogers (2016)) 'there is work to be done and it is ours to do.' This in turn reflects Arendt's account of political responsibility, the account which inspired Young's distinction between guilt and political responsibility. However, this interpretation of social connection is not in keeping with Young's view that political responsibility should track action and relations (see McKeown, 2018: 488).

\section{Reasonable Precautions}

The discussion above suggests that all those who are socially connected to structural injustice have duties to try to lessen it. However, it did not specify why responsibility to take action should be assigned on the basis of any of these connections. In the following section, I argue that the idea that social connection can constitute grounds for a demand that someone take action can be justified using the moral principle of taking reasonable precautions. Then I explain why likely future causal connection can ground a demand to take precautions even in cases where the same connection to past injustice cannot justify the attribution of blame or liability for it. Thus, I propose we settle on an account that recognises forward-looking obligations to address structural injustice as falling on those who are likely to causally contribute to its reproduction if it is not ended.

6 Ronald Dworkin's associative account of political obligations suggest that simply being born in to a particular community with a particular set of social conventions is 'pregnant with obligations' if certain conditions are met. If the community meets these conditions complying with the conventional demands made of members of that community becomes morally required (Dworkin, 1998: 202-215). In a similar way perhaps living within a social structure comes with a duty to try to promote justice within that structure. Alternatively, perhaps there is a convention under which members of political communities have a duty to try to regulate the structure under which they live in a way that promotes justice. If this were the case individuals connected to each other in a genuine community would have such duties according to Dworkins account. This is another way in which individuals can be 'socially connected.' However, it is not a route that Young explores because she is committed to the idea that it is an individual's connection to social structure or structural injustice that grounds the demand rather than membership in a political community - see Young (2011: 105) - where Young makes it clear that it is not sharing a common constitution that grounds the remedial responsibility. This suggests that her account is not that shared political institutions or sharing a coercive power that grounds the duty. Thus, she distinguishes her approach from that of Nagel (2005: 113-147). In doing so she leaves room for the idea that in certain conditions remedial responsibility for lessening injustice can cross state boundaries and be global or regional in scope. Her account suggests that when social structure is regional or global so are the responsibilities to ensure justice within that structure. 
Social structural analysis recognises persisting aspects of a society: ongoing systems of interaction between socially constituted groups that are unintentionally reproduced over time through the actions of individuals. Thus, any particular structural injustice will persist into the future unless it is addressed. I am proposing that it is the likelihood of contributing to future injustice, by reproducing existing structures, that explains why agents have obligations to work together in the present to try to prevent its continuance. This is in contrast to Young's account that implies we should look back to identify social connection to structural injustice and use this as a basis to assign remedial forward-looking duties without a clear explanation as to why it is that social connection can ground a forward-looking obligation. ${ }^{7}$ I propose that those who are likely to be socially connected to structural injustice in the future must take action in the present aimed at preventing that injustice from occurring. Although, individuals may not have been responsible for establishing the unjust structures within which they live, their ever day action will help to sustain these structures by reproducing them unless these structures are dismantled or subverted. As Young notes structural injustices are "reproduced through individuals' actions" (Young 2011, 59-62, McKeown 2018, 484, 488, $496,500)$. Thus, contemporary individuals risk contributing to the endurance of already established unjust structures unless they work with others to change their social order. They should seek to avoid contributing to the maintenance of unjust structures by working with others to alter these structures.

The moral demand to take such action is justified by the moral requirement that agents take reasonable precautions. In many cases we do not prohibit certain actions but instead require that those who take these actions engage in precautions that either reduce the seriousness of any harm they risk causing or reduce the risk of their causing that harm. For example, when people put on fireworks displays, they are morally required to take precautions that limit the risk of harming others and limit the seriousness of any harm they do cause (Kahn, 2014: 229). I am proposing that efforts to lessen on-going structural injustice are reasonable precautions that agents must take in order to limit their chances of contributing to structural injustice in the future by reproducing existing unjust structures. I argue that understanding the moral demand in this way explains both why agents must take such action and why they should not be blamed if they are causally connected to structural injustice in spite of making sufficient efforts to prevent that injustice.

7 Young's account could be interpreted as looking back in order to trace connection to structural injustice in order to identify who is likely to be contributing both then, now and in the future. According to this interpretation, looking back is simply a way of identifying causally relevant processes and contribution to those processes. This interpretation is in keeping with my account rather than opposed to it. 
Young explicitly rejects the liability model as a way of understanding responsibility with regards to structural injustice. She suggests that political responsibility is not about identifying a party to whose agency the outcome can be attributed. She suggests that the social connection model is forwardlooking in that it identifies a responsibility to act going forward rather than identifying responsibility for an outcome that has already occurred. However, she leaves unanswered the question as to why it is that individuals who are socially-connected to structural injustice are the ones who share responsibility to address it (Abdel-Nour, 2018; McKeown, 2018). My answer to this question suggests that both liability and political responsibility are explained by the same overall moral idea: that agents have duties to avoid harming each other. If this is right, then it suggests that the two different accounts share a common root: that, in order to understand why individuals have a responsibility to work together to lessen structural injustice, we must recognise the fact that if they do not remove the structural injustice they will end up contributing to its reproduction.

\section{Precautions over Restraint}

I will now explain why risk of causal contribution to future injustice can justify a requirement to take precautions rather than a duty not to contribute. I begin by explaining why there cannot be a strict moral prohibition on contributing to structural injustice.

The first problem with such a prohibition is that in many cases avoiding causal connection to any structural injustice is impossible. On the assumption that 'ought implies can,' this means that there cannot be a strict prohibition on such contributions. Due to the complexity of structural injustices, it is often not clear which actions are going to come together with those of others to cause a significant problem. This explains why agents typically should not be blamed for having some causal connection to past structural injustice: often they could not have avoided contributing.

However, the above argument doesn't negate the possibility that there could be a duty to avoid contributing to structural injustice to the extent that it is possible. As previously stated, social structures result from many actions coming together. It is often unclear which actions will contribute to the reproduction of structural injustice. Thus, the safest way to minimise contributions would be to withdraw from social life as far as possible: by doing so an agent minimises their chances of contributing to a social trend or practice that comes together with others to reproduce structural injustice. However, this is a highly burdensome requirement. Agents must participate in social life in order to live a minimally decent life. This is in part because collaborating with others and participating in supply chains is necessary if people are to secure the goods they need to live 
a minimally decent life. It is also due to the fact that living a good life requires interacting with others and being part of social practices that allow people to give meaning to their lives, and pursue the projects and goals they have reason to value. Complying with a demand to avoid causal connection to structural injustice wherever possible by refraining from actions likely to contribute to structural injustice would in all likelihood undermine agents' wellbeing and agency. Given the gravity of the burden that such a withdrawal places on an individual it is unlikely to be justifiable all things considered. Thus, we can reject a strict requirement to limit contributions to the reproduction of structural injustices to the extent that it is possible for them to do so on the grounds that it is unreasonably burdensome.

In response to the claim that a duty to avoid contributing to structural injustice, where possible, is too burdensome it could be argued that this does not mean there is never a duty to avoid such contributions. It could be that individuals have a duty to avoid contributing to structural injustices where doing so is not overly-burdensome. This means they should seek to stop contributing to trends and practices that are known factors in on-going structural injustices. This requires that people seek to identify systematic disadvantage to particular social groups and then identify contributing factors. Then those contributing to these factors must try to avoid so contributing in the future to the extent that it is reasonable to expect them to do so.

But this approach is epistemically demanding and exerts significant burdens on duty-bearers. Worse still, it is not likely to produce much benefit for the victims of structural injustice. Structural injustice is by definition an injustice that results from multiple social processes coming together. Typically, many different agents contribute to each contributory social process. In most cases preventing a structural injustice through restraint will require a vast number of agents to remove their contributions. This means that removing any particular contribution is extremely unlikely to make any victim better-off.

If there is an alternative way to avoid structural injustice that is likely to be more effective in preventing injustice and yet less demanding in the burdens it assigns, this alternative should be preferred. In most cases of structural injustice, injustice can most efficiently be avoided through agents in different positions working together to change the structure. These efforts could involve reorganising social practices, ending social trends through adopting new norms, introducing legal prohibitions, or instigating new structural factors that counter-act existing forces. Changing structures in these ways is likely to be both less costly and more effective than individuals limiting contributions to structural injustices: by coordinating their actions, agents can together 
take action that adjusts social structures so as to avoid structural injustice. If successful, this means they can continue to participate in social cooperation whilst avoiding structural injustice. Given this fact, morality should require that agents work together to prevent future structural injustice rather than requiring non-contribution where it is not too burdensome. A moral duty of restraint should be rejected because a less objectionable and more effective alternative is available: structural change. ${ }^{8}$

Success is not guaranteed when individuals make choices aimed at ending structural injustice through collective action. However, if such action is sensible and well thought-out, it will increase the chance of structural injustice being lessened and avoided. Those likely to contribute to structural injustice can be called on to take such action because complying with such a demand is the action most likely to minimise future structural injustice. Agents have a general duty to take such action because it increases the likelihood of achieving justice and avoiding suffering. The general duty to promote justice (Rawls, 1999: 99) grounds a duty to take such action (Stilz, 2019: 389). However, additional obligations can be assigned to those at risk of causally contributing to future structural injustice by reproducing existing structures. These agents are not simply bystanders who could improve circumstances. The fact that they are potential contributors means that they can also be asked to take such action as a reasonable precaution to lessen their chances of contributing to the reproduction of serious structural injustice in the future. Thus, social connection (understood as likely future causal contribution) is a ground on which an obligation to take action aimed at preventing structural injustice can be recognised: such action can be understood as a precaution to prevent connection to future structural injustice that it is reasonable to demand agents take. Obviously, the costs that any particular agent can be asked to take on must be restricted by what is reasonable. However, what is reasonable will depend on circumstances that include the seriousness and extent of the structural injustice.

Agents can fairly be judged on whether or not they comply with this requirement rather than whether or not they do in fact become causally connected to structural injustice in the future. Precautionary action may succeed or fail (or succeed to some extent). However, it is unfair to require agents to

8 The greatest objection to the co-ordination approach will be less weighty than the strongest objection to the constraint approach. If the strongest objection comes from the victims of structural injustice it will be greater against a schema less likely to end the injustice they face: the restraint-based approach is less likely to succeed in preventing their suffering and thus can be rejected on this basis. Even if the two proposals were equally likely to prevent the experience of acute structural injustice, there would still be reason to prefer the more efficient schema as it will burden those with duties less than the restraint-based approach without burdening further those at risk of essentially aggregative harm. For discussion of why the greatest complaint matters and the importance of interpersonal justification see Scanlon (2000) and Forst (2011). 
ensure success because this is beyond their control. What we can legitimately demand of them is that they make a reasonable effort to avoid future structural injustice when the injustice and their connection to it are foreseeable. Agents should only be subjected to moral blame and condemnation when they violate valid moral demands: it is wrong to blame them where they have not acted impermissibly. ${ }^{9}$ This means that because we cannot justify a moral demand to avoid causal connection to structural injustice we cannot blame agents for having such a connection. The fact that it is inappropriate to blame agents for their connection to structural injustice is noted by Young in her criticism of Christopher Kutz's treatment of 'unstructured collective harms' (Young, 2011: 102-104; Kutz, 2000). However, Lu suggests that agents can be blameworthy for their contributions to structural injustice (Lu, $2018: 48$ ).

The moral demand outlined above requires all those likely to be causally connected to future structural injustice to work together to efficiently prevent that injustice, fairly sharing the burdens of this task. But individual agents face an important difficulty in determining what duties precisely they owe. Many different factors (and the actions of many different individuals) come together to reproduce structural injustice; consequently, for any particular agent, there may be some doubt as to whether or not their actions have contributed to the reproduction of any particular structural injustice. Given this uncertainty, responsible agents should seek to address any structural injustices that they may contribute to the reproduction of. Agents can be blamed if they fail to meet this demand unless they have some acceptable excuse for their failure to act. It is important to note that there may be good reason for agents to focus their efforts on on one particular injustice. If they choose to do so this could excuse their failure to make progress on other injustices they might be connected to. A full account of duties with regards to structural injustice would need to consider such questions at length. However, there is not sufficient room to tackle this complex question here.

Iris Young's work suggests that those individuals who are socially connected to on-going structural injustice can be assigned remedial responsibility to lessen that injustice. I have proposed that it is the likelihood of an individual contributing to the reproduction of structural injustice that explains why socially connected individuals have such a responsibility. I have suggested that individuals must take action aimed at lessening structural injustice as a precaution aimed at avoiding future contribution to the reproduction of the injustice in question. My account explains why it is that causal connection grounds an extra duty

9 Thus, we should not recognise residual guilt as being appropriate in cases where an agent non-culpably is causally linked to a tragic outcome like the non-culpable lorry driver case (Contra Abdel-Nour (2018) and Williams (1981). 
in addition to the general duty to promote justice. Furthermore, I have shown why it is that agents can have a duty to take such precautionary action to lessen the chances of their contributing to the reproduction of significant structural injustice even when they cannot be blamed for causally contributing to such injustice if it does occur in spite of their efforts.

\section{From Shared Responsibility to Collectivization Duties}

Young and Lu's work suggests that there is a moral demand that falls on all those who are socially connected to injustice requiring that they take part in collective action aimed at lessening structural injustice ( $\mathrm{Lu}, 2017$ : 171, 258; Young, 2011: 111-113). This paper has proposed that social connection should be defined as likely causal connection to the reproduction of structural injustice and that the demand for action should be based on the principle that agents have a duty to take reasonable precautions to avoid contributing to harm. In this next section I consider how best to describe and understand what is required by the demand to take precautions to avoid contributing to future structural injustice. I propose that we use the concept of a 'collectivization duty' (Collins, 2013) to explain what agents are obliged to do. I begin by outlining Young's account of essentially shared, primarily forward-looking responsibility. I then propose an alternative way to define the moral demands that falls on those socially connected to structural injustice before outlining the advantages of this account. I argue that this approach can deal comprehensively with both Martha Nussbaum's (2011) critique of perpetually forward-looking accounts and the ‘agency objection' (Wringe, 2010).

In cases of structural injustice, the actions of a large set of individuals reproduce the on-going injustice. Young suggests that members of this inchoate group share responsibility to overcome the injustice. Lu also talks of these agents sharing moral responsibility (Lu, 2017: 164, 170, 173, 264). Young describes the responsibility as 'essentially shared' rather than collective. She explains that if the group itself had collective responsibility to tackle structural injustice then none of the members could be said to be responsible for the task. This is because collective responsibility, as Young understands it, is not distributable. In contrast to collective responsibility (that belongs to the collective agent and not to its members), Young thinks that political responsibility for lessening structural injustice must be distributable: each member of the aggregate must share responsibility. Thus, she suggests that the inchoate group of those socially connected to structural injustice share responsibility to lessen the structural injustice. She explains that each member of this aggregate has a responsibility to work towards overcoming the injustice but they bear this responsibility in the awareness that others also share in it (Young, 2011: 109-111). Young explains 
that fulfilling this responsibility requires that agents take part in collective action because structural injustice can only be lessened through such action (ibid.: 105, 111-113). Collective action occurs when agents self-consciously work together to produce an outcome by coordinating their action either through an explicit decision-making mechanism or through responsive action.

Young's requirement that collective action be taken in order to lessen structural injustice is plausible because structural injustice can only be overcome through systematic changes to the social structure of a society. Any instance of structural injustice is caused by multiple social processes coming together (ibid.: 43-59). Changing even one of these processes will require coordination between multiple individuals. Often multiple processes will need to be changed in order to address the injustice and thus coordination will need to be even more widespread. Introducing a new systematic element that can lessen structural injustice likewise will require multiple agents to change their action in a coordinated manner. Thus, overcoming or lessening structural injustice will require coordinated action between a number of individuals. This collective action could involve using an existing mechanism like government, establishing new mechanisms or developing and reproducing new informal norms. As Lu notes the state can be central to coordinating political responsibility at the domestic level, although to do so it will often need support from individuals and organisations. Furthermore, resolving global and transnational structural injustices will require cooperation with international and transnational institutions ( $\mathrm{Lu}, 2017: 265) .{ }^{10}$

Above it was argued that the moral demand that falls on those likely to be socially-connected to future structural injustice is based on the duty to take reasonable precautions. Precautions are actions agents take in order to reduce the likelihood and/or severity of problematic outcomes that they may cause. In the case of structural injustice an action that reduces the chance of

10 It is also important to note that because structural injustice concerns the way an agent is treated by a social system and not just the benefits and burdens an agent ends up with it cannot be addressed by offering compensation. Thus, no individual can stop a structural injustice just by transferring goods or money on an ad-hoc basis. What a wealthy individual could do is spend enough money to systematically change a situation: by launching a new enterprise, starting an NGO or convincing legislators to make changes, in doing so they will have to secure the cooperation of many other individuals. Thus, they will be using their funds to secure a collective action solution. Sometimes powerful individuals can make systematic changes, but this is only when large numbers of people change their actions or practices as a result of the powerful agent's decision. This is still a form of collective action just one coordinated by an individual whose directions are followed by many. In these cases, a set of agents act together on the basis of the directions of a leader. It is the actions of the group that overcome structural injustice. Thus, this is a case of collective action. Building upon Hannah Arendt's analysis it could be said that the group 'empower' the leader and it is their commitment to obeying the leader that is key (Arendt, 1970). When an agent has the ability to lessen structural injustice by directing the actions of others the group is already a collective in some sense. They are a set of agents with a decision-making mechanism (the leader makes the decisions). Where an individual has the ability to form such a group, forming such a group can be considered a responsive action that works towards forming a collective willing and able to lessen structural injustice. 
injustice continuing or reduces the severity of any likely injustice can count as a precaution. The duty to take precautions to avoid future contribution to structural injustice requires individuals to act in a complicated way. It requires they take action that increases the chance of a collective or coalition capable and willing of addressing structural injustice (directly or indirectly) existing.

Stephanie Collins has argued that when there is an urgent moral task that needs to be performed and yet there is no existing agent capable of performing the task individuals have duties to 'collectivize.' These duties require agents to 'perform responsive actions with a view to there being a collective that can reliably address the circumstance' (Collins, 2013: 231-248). ${ }^{11}$ Once such a collective is established, the collective gains a responsibility for fulfilling this task. This means that the collective's decision-making mechanism has a decisive moral reason to adopt a plan of action able to complete the task. And members of the collective then have a duty to perform the roles they are assigned by the collective. In addition, they retain a duty to monitor the collective and act upon it to try to get it to fulfil its duty if necessary.

The analysis here suggests that precautionary duties fall on all those at risk of causally contributing to future structural injustice. Yet those obliged to take precautions are not able to lessen structural injustice by acting unilaterally: what the precautionary duty requires of these agents is collectivization. For most agents with precautionary duties with regards to structural injustice, these duties require that they perform 'responsive actions' with a view to establishing and maintaining a collective that can reliably prevent future structural injustice. Fulfilling these duties is the precaution that agents have a pro tanto moral duty to take. Taking such responsive action reduces the risk of structural injustice continuing to emerge from an agent's actions along with the action of many other individuals and collectives. Agents who successfully form a collective able to tackle structural injustice must work towards ensuring that their collective does not violate any moral requirements and fulfills any appropriate legitimacy standards.

Thus, instead of positing a shared responsibility which is distributable, as Young's approach does, my approach recognises individual duties to collectivize. By understanding the requirement in this way, we recognise duties as falling on each individual who is likely to be causally connected to structural injustice and yet recommend a collective-action solution. Thus, in keeping with Young's recommendation we still require collective action and ensure each member of the aggregate is obligated. Collectivization duties require agents to act responsively with a view to establishing and maintaining a collective that

11 For an account of collectivization and the duties of states see Collins and Lawford-Smith (2016). 
prevents structural injustice from continuing. This means that once a capable collective is formed, each individual has a duty to act responsively with a view to ensuring the collective discharges this task.

The collectivization approach offers several advantages over essentially shared responsibility. Firstly, it does not involve applying responsibility for a task to an inchoate or amorphous group, a concern of both Lu and Stilz (Lu 2011: 172; Stilz, 2019). Those who are socially connected to structural injustice are not a collective agent but an aggregate. Whether moral demands can be applied to groups that are not agents is a controversial issue. By assigning individual duties to collectivize this problem is avoided. ${ }^{12}$

Secondly, the collectivization approach is better than an essentially shared responsibility because it makes moral demands of individual agents rather than stating that they share responsibility for ensuring an outcome. It is unfair to judge agents on the basis of factors that are beyond their control. The approach recommended here allows agents to be judged on their own choices alone. We can examine the facts concerning whether an agent has taken sufficient responsive action that promotes the formation of a collective that can reliably prevent future structural injustice. We can then praise or blame them on the basis of their own actions and omissions, given their context.

In contrast, it is not clear how to judge those agents who share in responsibility to lessen structural injustice (the way Young proposes we understand the obligation). In these cases, there is often no collective agent that can be blamed or praised on the basis of success or failure just as there is no collective agent who is responsible. Is the blame in the case of failure to be shared between the group? This might follow from the idea that they share the forward-looking responsibility and bare it in the knowledge that they bare it together as Young suggests (Young, 2011: 109-111). This would mean that if the inchoate group does not lessen structural injustice, then all members (including those who sincerely and ardently took sensible action in pursuit of the goal) would share in the blame. It would be unfair to blame agents who did all that could reasonably be asked of them in order to lessen injustice for the failure of the inchoate group to succeed in this task. The advantage of the 'collectivization duties' approach is that it means that agents are not blamed for the failure of others to collectivize.

Young does not endorse any account of praise or blame with regards to the failure or fulfilment of essentially shared forward-looking responsibility. Instead she insists that the point of her account is to assign responsibilities to take action to lessen injustice rather than to blame agents for what they did in

12 For discussion of whether aggregates can have responsibilities or duties see Collins (2017); Isaacs (2011); Kutz (2000); and Wringe (2010). 
the past. Thus, she insists that her account is primarily forward-looking (Young, 2011: 108-109). My account shares the emphasis on ex-ante action to prevent future injustice and even explains why there is this emphasis on the future: although agents cannot reasonably be expected to avoid causal connection to injustice, they can be expected to take precautions to lessen their chance of such a connection. However, when we assign responsibilities or duties, we are insisting that certain agents must take up certain tasks. It follows from such an assignment that as time passes agents can be judged on whether or not they have fulfilled the tasks or roles assigned. Thus, no account can only be forwardlooking. This is a fact that Martha Nussbaum recognises in her discussion in the forward to Young's book (Nussbaum, 2009).

The account of precautionary collectivization duties falling on those likely to be causally connected to future structural injustice outlined here takes on Nussbaum's challenge head on. It explains that the duties are primarily forward looking because they demand ex-ante action to avoid future injustice. However, this account explicitly endorses the fact that as time passes agents can be judged on their success or failure to take the responsive actions demanded. This is fair because it judges agents on their own choices. They are judged on whether they took sensible responsive actions aimed at establishing a collective to tackle structural injustice or ensuring an existing collective takes on the task. ${ }^{13}$

Replacing essentially shared, primarily forward-looking responsibility with a precautionary duty that requires collectivization preserves Young's aim of assigning obligations to take part in collective action aimed at lessening structural injustice. Yet it allows Nussbaum's objection to a perpetually forward-looking account to be met. The recommended approach assigns clear duties to all those likely to be causally connected to future structural injustice. It recommends that they pursue collective action and as time passes it allows them to be fairly judged on their own choices rather than those of others.

\section{Precautions Without Liability}

By combining a collectivization approach to duties to prevent future structural injustice, a precaution-based explanation of the reason why social connection grounds this moral demand, and a causal connection account of social

13 Where a collective capable of tackling structural injustice is established it can also be judged on its success in achieving this task. The blame or praise of any such collective will mean praise or blame for its members in terms of contributing to its maintenance and fulfilling their roles within it. The question of what duties agents have once a collective is established is an interesting one which in turn will lead to conclusions concerning judgements made of individuals in cases of the success or failure of that collective. Unfortunately, a detailed account of this cannot be made here for reasons of space. However, the collectivization approach gives a means to addressing these difficult questions. Some work on the question of how duties change as collectives are established has already been done (Collins and Lawford Smith, 2016). In cases of structural injustice, it is often political institutions that offer the best means to avoiding structural injustice. However, where these institutions are difficult to establish or resistant to demands to act there may be other forms of collective action that can lessen structural injustice. 
connection I have proposed a solution to the questions raised regarding Young and Lu's approaches (Stilz, 2019). I have agreed that social connection grounds a moral demand to work with others with the aim of preventing or lessening structural injustice through collective action. I have defined social connection as causal contribution to processes that together cause or constitute injustice. I have identified that this demand derives from the duty to take reasonable precautions to avoid contributing to harm. Finally, I have insisted that this demand will require collectivization. The account outlined here suggests that, in response to on-going structural injustice, those likely to be causally connected to that injustice in the future have precautionary duties that require them to take responsive actions capable of establishing a collective that can reliably address this injustice.

Young rejects the liability approach to responsibility and structural injustice. Yet the approach proposed here is similar in a number of ways. It bases duties to act on causal connection to structural injustice and calls on agents to take action to avoid such connection. Furthermore, it involves blaming agents on the basis of whether they do or do not make collectivisation efforts. I will now briefly consider whether problems with using the liability approach apply to the precautionary approach outlined above.

The chief objection Young has against the liability approach is that it attaches blame. She argues that from a pragmatic perspective this is a bad idea when it comes to structural injustice (Young, 2011: 113-122). The precautionary approach does not attach blame on the basis of causal connection to structural injustice. However, it does involve the condemnation of those who fail to take up their precautionary obligations. This is in keeping with Young's assertion that those who fail to fulfil their forward-looking responsibility should be criticised (Young 2011: 144, quoted in Lu 2018b: 47-48). In the present, it both encourages agents to take action to prevent future structural injustice and condemns or praises them on the basis of the precautions they took or failed to take in the past. Although, this blame for inaction may result in some negativity, it is an inevitable part of any account that assigns duties or responsibilities to take action that as time passes it will lead to praise or condemnation on the basis of whether or not those duties or responsibilities are fulfilled. This follows directly from the logic of moral demands as Nussbaum recognises in her critique of Young's account (Nussbaum, 2009).

A second problem with assigning moral responsibility on the basis of causal connection is, that it is unfair because it means that agents are blamed for what they cannot necessarily avoid. In contrast, the approach proposed here judges agents on what is within their control: it judges them on the basis of whether 
they take sufficient responsive action to establish a collective that can reliably prevent structural injustice. Thus, the precautionary approach is not subject to this problem.

A third problem with the liability approach highlighted by Young is that it is isolating: it singles out some for blame and thereby absolves others (Young, 2011: 105-107). However, this is not the case with the precautionary principle identified here. This is not because it concerns precautions. It is because it identifies all those causally connected rather than highlighting one action as the cause amongst a series of conditions. As a result, more than one agent is required to take precautions. Finding a potential future causal connection between an agent and a structural injustice does in no way exclude finding a potential future connection between another agent and the same problem.

A fourth problem with the liability approach identified by Young is that it is used to identify an agent who can be held causally responsible (Young, 2011: 95-97). This is not the aim of the precautionary approach. It does not rely on one causal contribution being selected and identified as morally responsible. Instead it identifies all likely future contributors to the reproduction of structural injustice and calls on them to act. The usual way of understanding precautionary duties is to assign them to those who will be found outcome responsible if the consequence actually occurs. In contrast the precautionary approach recommended here, identifies all those likely to contribute to the reproduction of structural injustice and holds each of them responsible for taking precautions to avoid its continuance.

\section{Conclusion}

What is being proposed is that individuals likely to be causally connected to future structural injustice have a collectivization duty that requires they take responsive action aimed at establishing a collective that can reliably address that structural injustice. I have proposed that taking such action is a precaution that we can reasonably demand they take.

The aim of this project has been to come up with an account of moral demands that fall on agents with regards to structural injustice on the basis of their social connection to it and to explain how their connection could ground duties. I hope to have offered a plausible account of such demands that can meet some of the problems with Young's own articulation of responsibilities with regards to structural injustice as well as some of the questions raised regarding Lu's use of it.

With regards to structural injustice there are likely to be positive duties to prevent its continuance through collectivization. A general duty to promote 
justice (Rawls, 1999) surely requires agents collectivize to prevent future structural injustice. However, in addition, it is important to recognise duties that fall on those likely to contribute to future structural injustice because of that likely connection. Doing so draws attention to the fact that the task of avoiding structural injustice is also required in order to avoid causally contributing to future injustice. Emphasising that injustice results from human action in addition to recognising that people can promote a more just future is important for both Lu and Young's projects. The purpose of developing a precautionary account is to draw attention to the relational nature of justice and our duties with regards to it. Instead of beginning from what an ideal social scenario would be and then assigning duties to bring it about, this approach looks at existing injustices and asks what duties agents have to prevent them continuing. I do not have room to fully defend the importance and plausibility of such an approach here. However, I hope to have offered a plausible way of articulating and explaining the moral demand to take political action that results from social connection.

\section{Elizabeth Kahn}

Assistant Professor in Political Theory

School of Government and International Affairs

The University of Durham

email:elizabeth.kahn@durham.ac.uk

\section{- the global justicenetwork}




\section{Bibliography}

Abdel-Nour F (2018) Responsibility for structural injustice. Ethics \& Global Politics 11(1): 13-21. Arendt H (1970) On Violence. Orlando: Houghton Mifflin Harcourt.

Berger PL and Luckmann T (1991) The social construction of reality: A treatise in the sociology of knowledge. London: Penguin UK.

Collins S (2013) Collectives' duties and collectivization duties. Australasian Journal of Philosophy 91(2): 231-248.

Collins S and Lawford-Smith H (2016) The transfer of duties: From individuals to states and back again. In Brady MS and Fricker M (eds) The Epistemic Life of Groups. Oxford: Oxford University Press: 150-172.

Collins S (2017) Duties of group agents and group members. Journal of Social Philosophy 48(1): 38-57.

Delmas C (2014) Political resistance: a matter of fairness. Law and Philosophy 33(4): 465-488.

Digeser PE (2018) Motivation and reconciliation in Catherine Lu's conception of global justice. Ethics \& Global Politics 11(1): 6-12.

Dworkin R (1998) Law's empire. Oxford: Hart Publishing.

Forst R (2011) The right to justification: Elements of a constructivist theory of justice. New York: Columbia University Press.

Isaacs T (2014) Collective responsibility and collective obligation. Midwest Studies in Philosophy 38(1): 40-57.

Jenkins R (2013) Pierre Bourdieu. London; New York: Routledge.

Jubb R (2012) Contribution to collective harms and responsibility. Ethical Perspectives 19(4): 733-764.

Jubb R (2013) Social connection and practice dependence: some recent developments in the global justice literature: Iris Marion Young, Responsibility for Justice. Oxford: Oxford University Press (2011); and Ayelet Banai, Miriam Ronzoni and Christian Schemmel, Social Justice, Global Dynamics. Oxford: Routledge, 2011. Critical review of international social and political philosophy 16(5): 698-713.

Julius AJ (2003) Basic structure and the value of equality. Philosophy \& Public Affairs 31(4): 321-355.

Kahn E (2014) The tragedy of the commons as an essentially aggregative harm. Journal of Applied Philosophy 31(3): 223-236.

Kutz C (2007) Complicity: Ethics and law for a collective age. Cambridge: Cambridge University Press.

Lawford-Smith H (2015) Unethical consumption and obligations to signal. Ethics \& International Affairs 29(3): 315-330. 
Lu C (2017) Justice and Reconciliation in World Politics. Cambridge: Cambridge University Press.

Lu C (2018a) Redressing and addressing colonial injustice. Ethics \& Global Politics 11(1): 1-5.

Lu C (2018b) Responsibility, Structural Injustice, and Structural Transformation. Ethics \& Global Politics 11(1): 42-57.

McKeown M (2018) Iris Marion Young's "Social Connection Model” of Responsibility: Clarifying the Meaning of Connection. Journal of Social Philosophy 49(3): 484-502.

Marin M (2017) Connected by Commitment: Oppression and Our Responsibility to Undermine it. Oxford: Oxford University Press.

May L (2002) Complicity: Ethics and Law for a Collective Age. The Philosophical Review 111(3): 483-486.

Merton RK (1949) Social Theory and Social Structure. New York: The Free Press.

Miller D (2007) National responsibility and global justice. Oxford: Oxford University Press.

Mills C W (2005) “Ideal theory" as Ideology. Hypatia 20(3): 165-184.

Nagel T (2005) The problem of global justice. Philosophy \& public affairs 33(2): 113-147.

Nussbaum M (2009) Iris Young's Last Thoughts on Responsibility for Global Justice. In Ferguson A and Nagel M (eds) Dancing with Iris: The Philosophy of Iris Marion Young. New York: Oxford University Press: 133-147.

Olsaretti S (2009) Responsibility and the Consequences of Choice. Proceedings of the Aristotelian Society Vol. 109 1(2): 165-188.

Rawls J (1999) A Theory of Justice. Cambridge MA: Harvard University Press.

Rogers M (2016) What good is history for African Americans?. Boston Review. Available at: http://bostonreview.net/editors-picks-us/melvin-rogers-what-good-history-african-americans (accessed: 22 July 2019).

Scanlon T (1998) What we owe to each other. Vancouver: Harvard University Press.

Stilz A (2019) Review of Catherine Lu: Justice and Reconciliation in World Politics. Criminal Law and Philosophy 13: 385-392.

Wringe B (2010) Global obligations and the agency objection. Ratio 23(2): 217-231.

Young IM (2011) Responsibility for Justice. Oxford: Oxford University Press. 